\title{
Epidemic Outbreaks in Plovdiv Region (Bulgaria) of Vaccine-Preventable Diseases: Measles, Mumps, Hepatitis A (2006-2010)
}

\author{
Nikolay Todorov Vatev ${ }^{1 *}$, Mariyana Vartigova Stoycheva², Andrei Ivanov Petrov², \\ Rayna Dimitrova Velcheva ${ }^{2}$ \\ ${ }^{1}$ Department of Hygiene, Ecology and Epidemiology, Medical University, Plovdiv, Bulgaria; ${ }^{2}$ Department of Infectious Diseases, \\ Parasitology and Tropical Medicine, Medical University, Plovdiv, Bulgaria. \\ Email: "nikolay_vatev@abv.bg, mariana_stoycheva@yahoo.com,dr_andre_petrov@yahoo.com, \\ rayna.velcheva@email.bg
}

Received March 26 ${ }^{\text {th }}, 2012$; revised April 28 ${ }^{\text {th }}, 2012$; accepted May 30 ${ }^{\text {th }}, 2012$

\begin{abstract}
Aim: To analyze the reasons for epidemic outbreaks of measles, mumps and viral hepatitis A and to propose measures to prevent them in future. Materials and Methods: The incidence of measles, mumps and hepatitis A in Plovdiv region was studied for the period 2006-2010. An analysis of the age structure of the patients was made, while taking into account the time for routine immunization performed against measles and mumps (first and second dose). Results: In 2006-2009 single cases of measles were found occasionally, but in 2010 they were 2787 (incidence 395/100,000). Most of them (51\%) were for ages 13 months - 12 years, $27 \%-0-13$ months and $11 \%-13$ to 18 years. The incidence of mumps for 2006-2010 varied widely, and has increased significantly in $2007(130 / 100,000)$ and $2008(169 / 100,000)$. The majority of patients (over 34\%) during the epidemics were aged 13 months - 12 years, and over $26 \%$ of them-13 19 years. For the period 2006-2010 the incidence of hepatitis A ranged from 2.98/100,000 (2009) to 426/100,000 (2006). Over $50 \%$ of the cases involved children aged up to 9 years. For the three diseases over $80 \%$ of patients were individuals of Roma origin. Conclusions: 1) Epidemic spread of measles in 2010 was mainly due to shortcomings in the routine immunization carried as a prevention of the disease. 2) There are two reasons for the outbreak of mumps: a) Failure to administer the second vaccine dose at 12 years in Bulgaria until 2001; b) Shortcomings in routinely performed immunization. 3) The extremely high incidence of hepatitis A in 2006 (and in the rest of the years) is due to the lack of routine immunization. 4) Essential for the outbreaks in all three diseases are the poor hygienic living conditions, the low social status and the lack of health promotion of the population at risk. 5) To prevent future outbreaks of the diseases hereby in question, we suggest it is appropriate: a) To introduce compulsory immunization against hepatitis A; b) To carry out periodic catch-up vaccination campaigns against measles and mumps.
\end{abstract}

Keywords: Vaccine Preventable Diseases; Measles, Mumps; Hepatitis A; Outbreaks

\section{Introduction}

Measles, mumps and hepatitis A (HAV) are vaccine preventable diseases - for the three of them there are elaborated vaccines with proved effect. The immunizations against measles and mumps are routinely implemented in many countries in the world during 1970-75. The grant of license for the vaccines against HAV and their use in the different countries is done during the period 1995-2000. Nevertheless for the last 5 - 6 years (2006-2010) in many countries epidemic outbreaks for all three diseases have been registered.

Measles: in France during 2008 - 604 cases [1]; in Ire-

${ }^{*}$ Corresponding author. land from August 2009 to 2010-320 cases [2]; in Germany from 15.03 .2010 to $19.05 .2010-71$ cases [3]; in Poland for 2009-40 cases [4]. In Slovenia 2 cases of measles as nosocomial infection have been registered in March 2010 [5]. In Greece from January to July 2010 126 cases have been announced, connected with the epidemic outbreak in Bulgaria [6].

Mumps: from June 2009 to July 2010 more than 1500 cases have been registered in New York and New Jersey [7]; from December 2009 to 20.04 .2010 - 172 cases in Netherlands [8]; from 01.07. to 31.10.2010 in Bavaria (Germany) 105 laboratory confirmed cases with 1 complication of meningitis and 21 with orchitis were announced [9]; from January 2008 to June 2009 in Mace- 
donia 16,352 cases were announced [10]; in Izrael (district Jerusalem) from September 2009 to 07.12.2009173 cases have been revealed [11].

HAV: in the Europe Union countries during 2008 there were independent epidemic outbreaks in the Czeck Republic, Latvia and Slovakia [12-14]. In France, Belgium and Germany in 2008 epidemic outbreaks were also registered among travelers, who have been on cruise in Egypt [15-17].

The aim of the study is to analyze the causes for the epidemic outbreaks of measles, mumps and HAV in Plovdiv region and to give recommendations for their prevention in the future.

\section{Materials and Methods}

The incidence rate of measles, mumps and hepatitis $\mathrm{A}$ in Plovdiv region, Bulgaria has been studied for the period 2006-2010. The data were taken from the documents of the Clinic for Infectious Diseases (Plovdiv) and from the Regional Health Inspection (Plovdiv). The diagnosis of the diseases was determined in accordance with the standards of the World Health Organization for notification and case classification of the infectious diseases. The serological tests were performed in the Department of Microbiology, Virology and Immunology-Medical University, Plovdiv. An analysis of the age distribution of the patients has been done. The age groups among the patients with measles and mumps were formed in con- cordance with the age of the routine immunizations against the diseases $\left(1^{\text {st }}\right.$ and $2^{\text {nd }}$ dose $)$. The age groups were as follows: 0 - 15 months (age before the application of the $1^{\text {st }}$ dose); 16 months - 12 years (the period between the application of the $1^{\text {st }}$ and the $2^{\text {nd }}$ dose); 13 18 years (children to whom the two doses were applied); 19 - 35 years (young people, born after the implementations of the vaccines against measles and mumps in Bulgaria); over 35 years (persons, born before the implementation of the immunizations). For the patients with hepatitis A the age groups were structured in a different manner, because the vaccine against HAV is not implemented as routine in Bulgaria.

\section{Results}

For the period 2006-2009 isolated cases of measles have been found-one in 2006 and one more in 2008. For 2007 and 2009 there are no reported cases of measles. In 2010 the incidence increased sharply-emerging diseases were 2787 (incidence 395/100,000)_Figure 1.

The majority of the patients $(51 \%)$ in 2010 were aged from 15 months (the time for immunization-13 months and immunity building) up to 12 years (time limit for re-immunization). $19 \%$ of the cases were infants, and $13 \%$-adolescents aged 13 - 18 years. A sizable number $(12 \%)$ of the cases were in persons aged $19-34$ years. Cases in the age group $>35$ years were comparatively small in number (Table 1).

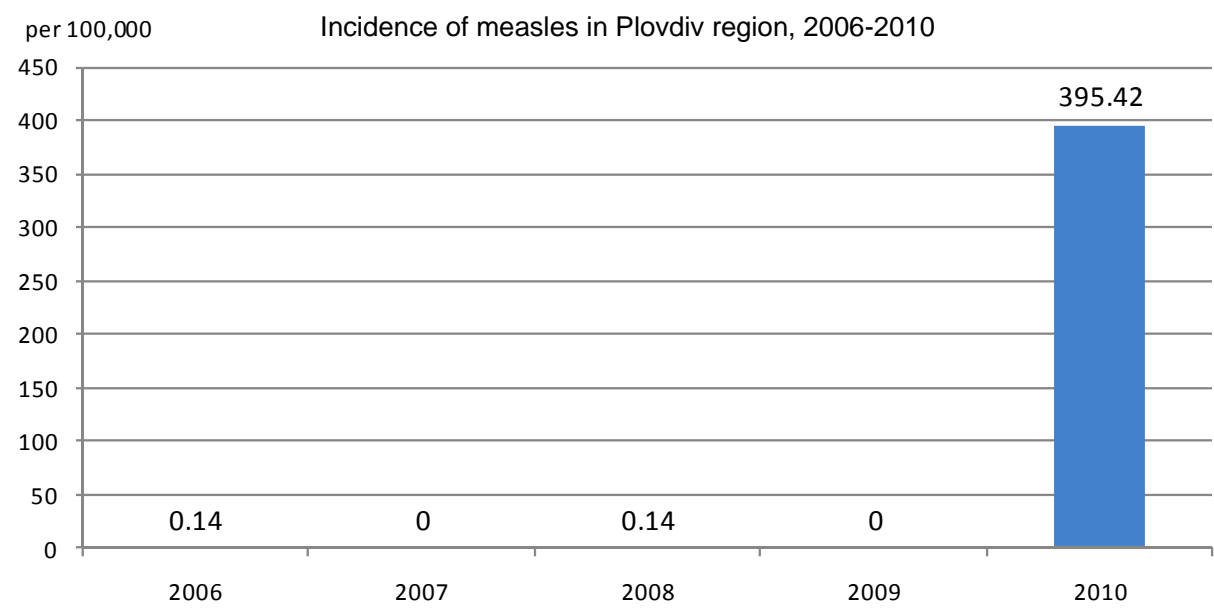

Figure 1. Incidence of measles in Plovdiv region, 2006-2010.

Table 1. Age structure of the patients with measles in Plovdiv region, 2006-2010.

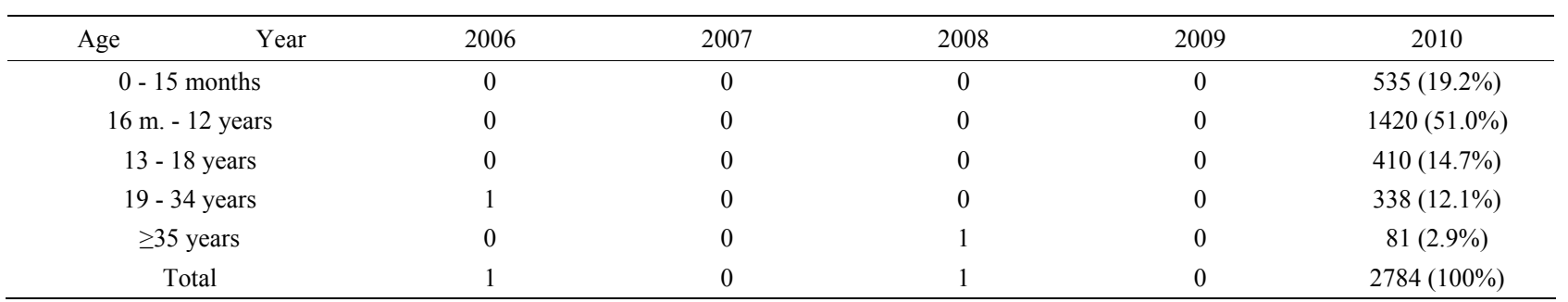


The incidence of mumps for 2006-2010 varied widely, and was increased significantly in 2007 (130/100,000) and 2008 (169/100,000). The number of registered cases was as follows: 2006-2; 2007-924; 2008-1201; 2009-158; 2010-14 (Figure 2).

The majority of the patients (over 39\%) during the epidemic years were aged 16 months - 12 years and over $26 \%$ were in the age range $13-18$ years. The number of cases aged 19 - 34 years is considerable-26\%. The number of patients in the other age groups is relatively small (Table 2).

During the study period, the incidence of HAV ranged from 2.98/100,000 (2009) to 426/100,000 (2006) - Figure 3. During the epidemic 2006, 44 epidemic outbreaks were registered, the broadest of them including 1004 patients. The low incidence in 2008 and 2009 is the result of the immunization campaign in October 2006, whereby $86 \%$ of children in Roma neighborhoods of the city aged 2 - 18 years were immunized.

Analysis of the age structure of patients with HAV found that the highest number $(29.89 \%)$ of cases were in children aged 5 - 9 years, followed by age groups of $0-4$ years $(19.71 \%)$ and $10-14$ years $(13.30 \%)$. Compared to previous studies, a higher proportion of the cases are in older age groups: 20 - 29 years $(10.6 \%) ; 30$ - 39 years

\section{(7.16\%) and 40 - 49 years $(5.88 \%)$ - Table 3.}

For all three diseases over $80 \%$ of patients were persons of Roma origin.

\section{Discussion}

With the implementation of the vaccine against measles as routine in 1972, the incidence rate of the disease in Bulgaria was significantly reduced starting from 1977. However, epidemic outbreaks were notified in 1981-1982 and 1992. The last one (in 1992) was implicated for lack of a second dose MMR at 12 years of age which was introduced in the end of 1992. The latest resurgence of measles in Bulgaria began in April 2009. To the end of 2010 a total of 24,233 cases have been notified with 24 deaths. Epidemic outbreaks of measles were notified in other countries too, but from the notified for 2010 about 30,000 measles cases in Europe [18] the greatest number was from Bulgaria-21,766 (over 70\%).

The analysis of the data shows that the cases of measles among children, aged 16 months to 12 years, may be explained with the fact that they have not received the $1^{\text {st }}$ dose of the vaccine (at 13 months). The cases among teenagers from $13-18$ years are due to the fact that they have not been immunized with the $2^{\text {nd }}$ (or both $1^{\text {st }}$ and $2^{\text {nd }}$ ) dose at 12 years.

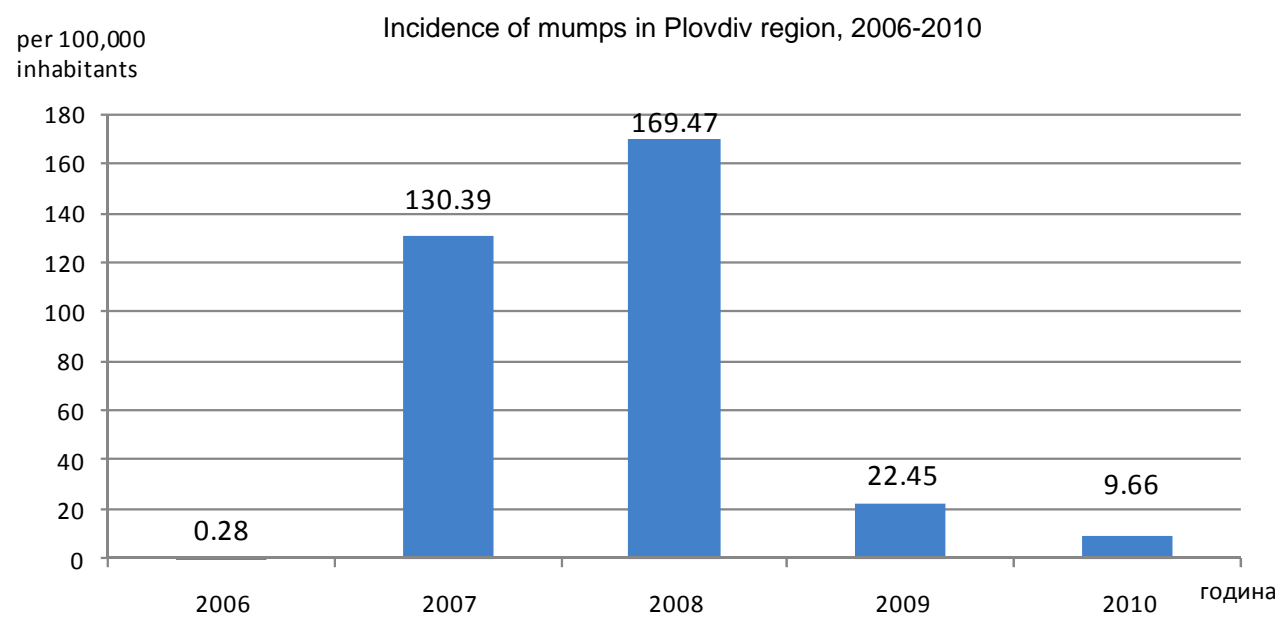

Figure 2. Incidence of mumps in Plovdiv region, 2006-2010.

Table 2. Age structure of the patients with mumps in Plovdiv region, 2006-2010.

\begin{tabular}{|c|c|c|c|c|c|}
\hline Year & 2006 & 2007 & 2008 & 2009 & 2010 \\
\hline $0-15$ months & 0 & $3(0.3 \%)$ & $7(0.6 \%)$ & $8(5.1 \%)$ & $1(1.5 \%)$ \\
\hline $16 \mathrm{~m} .-12$ years & 0 & $415(44.9 \%)$ & $413(34.4 \%)$ & $60(37.9 \%)$ & $25(36.8 \%)$ \\
\hline $13-18$ years & 2 & $247(26.7 \%)$ & $316(26.3 \%)$ & $35(22.1 \%)$ & $19(27.9 \%)$ \\
\hline 19 - 34 years & 0 & $198(21.4 \%)$ & $357(29.7 \%)$ & $40(25.3 \%)$ & $17(25.0 \%)$ \\
\hline$\geq 35$ years & 0 & $61(6.6 \%)$ & $108(9.0 \%)$ & $15(9.5 \%)$ & $6(8.8 \%)$ \\
\hline Total & 2 & $924(100 \%)$ & $1201(100 \%)$ & $158(100 \%)$ & $68(100 \%)$ \\
\hline
\end{tabular}




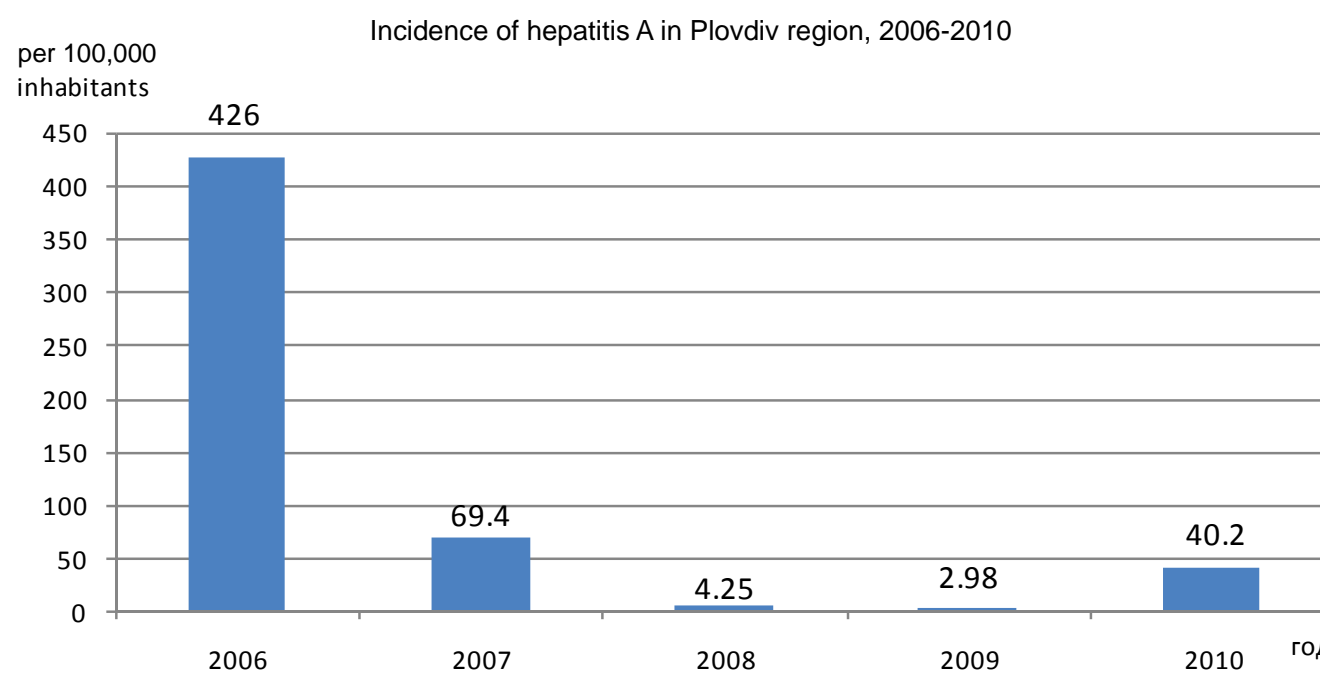

Figure 3. Incidence of hepatitis A in Plovdiv region, 2006-2010.

Table 3. Age structure of the patients with HAV in Plovdiv region, 2006-2010.

\begin{tabular}{|c|c|c|c|c|c|c|c|}
\hline Age & Year & 2006 & 2007 & 2008 & 2009 & 2010 & All \\
\hline $0-4$ & & $699(23.2 \%)$ & $49(9.9 \%)$ & $5(16.7 \%)$ & $1(4.8 \%)$ & $3(1.1 \%)$ & 757 (19.7\%) \\
\hline $5-9$ & & $1048(34.8 \%)$ & $83(16.9 \%)$ & $2(6.7 \%)$ & $2(9.5 \%)$ & $111(39.2 \%)$ & $1,148(29.9 \%)$ \\
\hline $10-14$ & & $385(12.8 \%)$ & $58(11.8 \%)$ & $0(0 \%)$ & $1(4.8 \%)$ & $67(23.7 \%)$ & $511(13.3 \%)$ \\
\hline $15-19$ & & $212(7.0 \%)$ & $63(12.8 \%)$ & $4(13.3 \%)$ & $1(4.8 \%)$ & $25(8.8 \%)$ & $305(7.9 \%)$ \\
\hline $20-29$ & & $279(9.2 \%)$ & $91(18.5 \%)$ & $6(20.0 \%)$ & $2(9.5 \%)$ & $30(10.6 \%)$ & $408(10.6 \%)$ \\
\hline $30-39$ & & $184(6.1 \%)$ & $66(13.4 \%)$ & $4(13.3 \%)$ & $9(42.8 \%)$ & $12(4.2 \%)$ & $275(7.2 \%)$ \\
\hline $40-49$ & & $156(5.2 \%)$ & $48(9.7 \%)$ & $6(20.0 \%)$ & $4(19.0 \%)$ & $12(4.2 \%)$ & $226(5.9 \%)$ \\
\hline $50-59$ & & $47(1.5 \%)$ & $26(5.3 \%)$ & $2(6.7 \%)$ & $1(4.8 \%)$ & $16(5.6 \%)$ & $92(2.4 \%)$ \\
\hline$>60$ & & $4(0.1 \%)$ & $8(1.6 \%)$ & $1(3.3 \%)$ & $0(0 \%)$ & $7(2.5 \%)$ & $20(0.5 \%)$ \\
\hline Total & & 3014 & 492 & 30 & 21 & 283 & 3840 \\
\hline
\end{tabular}

The demographic characteristics of the cases shows that measles is registered in over $95 \%$ among persons of Roma origin. While studies from other countries [19] reveal that a considerable part $(21 \%)$ of the measles cases are among foreign visitors or imported from neighbor countries [20], in Bulgaria the main risk group is the Roma population. The cause is the low vaccination coverage among them because of the intensive migration and the low health culture.

Similar (as for measles) are the causes for the mumps cases in the respective age groups. The difference here is that the $2^{\text {nd }}$ dose against mumps (at 12 years) was not included in the immunization calendar of Bulgaria until 2000. The results, obtained during the study, are in correspondence with these, established from another Bulgarian author [21]. But the cases of mumps observed by us (2125) in 2007-2008 are several times more than the cases, described from other authors during epidemic outbreaks: Whelan J. et al.-172 [8]; Otto W. et al.-115
[9]; Stein-Zamir C. et al.-173 [11]. A similar to the Bulgarian large outbreak of mumps with 16,352 cases for 2008-2009 was described only in Macedonia [10]. The cases in Bulgaria for 2007-2008 were about 20,000. These data show that the immunization coverage in these countries is not at a good level.

The epidemic outbreaks of HAV included predominantly patients of Roma origin (this tendency was observed for measles and mumps too) and affected more often the age group 5 - 9 years. The main risk factors for the epidemic outbreaks of HAV are the bad hygienic conditions of life and overpopulated households. The vaccine against hepatitis $\mathrm{A}$ is not implemented as routine in Bulgaria. This fact, combined with the bad hygienic habits and conditions of life of the Roma population, is the cause for the high incidence rate of hepatitis $\mathrm{A}$ in the country. It is from $30-40 / 100,000$ to $80-90 / 100,000$, as in endemic years reaches above 100/100,000. In 2006 the incidence rate of hepatitis A in Plovdiv region was 426/ 
100,000 .

\section{Conclusions}

1) Epidemic increase in the incidence of measles in 2010 was mainly due to gaps in routine immunizations against the disease. 2) The reasons for the epidemic of mumps are two: a) Failure to apply of the second vaccine dose at 12 years in Bulgaria until 2001; b) Shortcomings in routine immunizations. 3) The extremely high incidence of hepatitis A in 2006 (and in the other years) is due to lack of routine immunizations. 4) Essential for the occurrence of outbreaks in the three diseases are poor hygienic living conditions, low social status and health literacy of the population at risk. 5) To prevent future outbreaks of the studied diseases, we consider appropriate: a) Introduction of compulsory immunization against hepatitis A; b) Carrying out of periodic catch-up immunization campaigns against measles and mumps.

\section{REFERENCES}

[1] D. Waku-Kouomou, F. Freymuth, I. P. du Chatelet, T. F. Wild and B. Horvat, "Co-Circulation of Measles Virus Genotypes during an Epidemic in France in 2008," Journal of Medical Virology, Vol. 82, No. 6, 2010, pp. 10331043. doi: $10.1002 / j m v .21766$

[2] S. Gee, S. Cotter and D. O. Flanagan, "Spotlight on Measles 2010: Measles Outbreak in Ireland," Eurosurveillance, Vol. 15, No. 3, 2010, pii=19500.

[3] H. Roggendorf, A. Mankertz, R. Kundt and M. Roggendorf, "Spotlight on Measles 2010: Measles Outbreak in a Mainly Unvaccinated Community in Essen, Germany, March-June 2010," Eurosurveillance, Vol. 15, No. 26, 2010, pii $=19605$.

[4] H. Ortikova, J. Rogalska, E. Kazanovska-Zielinska, T. Jankovski, J. Stodzinski, B. Kass and P. Stefanoff, "Spotlight on Measles 2010: A Measles Outbreak in a Roma Population in Pulawy, Eastern Poland, June to August 2009," Eurosurveillance, Vol. 15, No 17, 2010, pii= 19550.

[5] N. Siegfried, C. Wlisong and D. Pienaar, "Too Little, Too Late: Measles Epidemic in South Africa," The Lancet, Vol. 376, No. 9736, 2010, p. 160. www.thelancet.com

[6] D. Pervanidu, E. Horefti, S. Patrinos, T. Lytras, E. Triantafillou, A. Mentis, S. Bonavas and T. Panagiotopoulos, "Spotlight on Measles 2010: Ongoing Measles Outbreak in Greece, January-July 2010," Eurosurveillance, Vol. 15, No. 30, 2010, pii=19629.

[7] C. S. Moyer, "Mumps Immunity Falls below Optimal Level," American Medical News, 2010. amednews.com

[8] J. Whelan, R. van Binnendijk, K. Greenland, E. Fanoy, M. Khargi, K. Yap, H. Boot, N. Veltman, C. Swaan, A. van der Bij, H. de Melker and S. Hahné, "Ongoing Mumps Outbreak in a Student Population with High Vaccination Coverage, Netherlands, 2010," Eurosurveillance, Vol. 15,
No. 17, 2010, pii=19554.

[9] W. Otto, A. Mankertz, S. Santibanez, H. Saygili, J. Wenzel, W. Jilg, W. F. Wieland and S. Borgmann, "Ongoing Outbreak of Mumps Affecting Adolescents and Young Adults in Bavaria, Germany, August to October 2010," Eurosurveillance, Vol. 15, No. 50, 2010, pii= 19748.

[10] G. Kuzmanovska, A. Polozhani, V. Mikik, K. Stavridis, B. Aleksoski, Z. Cvetanovska, R. Binnendijk and G. Bosevska, "Mumps Outbreak in the Former Yugoslav Republic of Macedonia, January 2008-June 2009: Epidemiology and Control Measures," Eurosurveillance, Vol. 15, No. 23, 2010, pii=19586.

[11] C. Stein-Zamir, H. Shoob, N. Abramson, E. Tallen-Gozani, I. Sokolov and G. Zentner, "Mumps Outbreak in Jerusalem Affecting Mainly Male Adolescents," Eurosurveillance, Vol. 14, No. 50, 2009, pii=19440.

[12] J. Cástková and C. Beneš, "Increase in Hepatitis A Cases in the Czech Republic in 2008-Update," Eurosurveillance, Vol. 14, No. 3, 2009, pii=19091.

[13] J. Perevoscikovs, I. Lucenko, S. Magone, A. Brila, J. Curikova and H. Vennema, "Community-Wide Outbreak of Hepatitis A in Latvia in 2008-An Update," Eurosurveillance, Vol. 14, No. 3, 2009, pii=19092.

[14] L. Hrivniaková, M. Sláčiková and S. Kolcunová, "Hepatitis A Outbreak in a Roma Village in Eastern Slovakia, August-November 2008," Eurosurveillance, Vol. 14, No. 3, 2009, pii=19093.

[15] E. Couturier, A. M. Roque-Afonso, M. J. Letort, E. Dussaix, V. Vaillant and H. de Valk, "Cluster of Cases of Hepatitis A with a Travel History to Egypt, SeptemberNovember 2008, France," Eurosurveillance, Vol. 14, No. 3, 2009, pii=19094.

[16] E. Robesyn, M. I. Micalessi, S. Quoilin, M. Naranjo and I. Thomas, "Cluster of Hepatitis A Cases among Travellers Returning from Egypt, Belgium, September through November 2008," Eurosurveillance, Vol. 14, No. 3, 2009, pii $=19095$.

[17] H. Bernard and C. Frank, "Cluster of Hepatitis A Cases among Travellers Returning from Egypt, Germany, September through November 2008," Eurosurveillance, Vol. 14, No. 3, 2009, pii=19096.

[18] European Centre for Disease Prevention and Control (ECDC), "Epidemiological Update on Measles in EU/ EEA,” ECDC, Stockholm, 2011.

http://www.ecdc.europa.eu/en/activities/sciadvice/Lists/E CDC\%20Reviews/ECDC_DispForm.aspx?List=512ff74f $\% 2 \mathrm{D} 77 \mathrm{~d} 4 \% 2 \mathrm{D} 4 \mathrm{ad} 8 \% 2 \mathrm{Db} 6 \mathrm{~d} 6 \% 2 \mathrm{Dbf0f} 23083 \mathrm{f} 30 \& \mathrm{ID}=10$ $46 \&$ Source $=$ http $\% 3 \mathrm{~A} \% 2 \mathrm{~F} \% 2 \mathrm{Fwww} \% 2$ Eecdc $\% 2$ Eeuropa $\% 2 \mathrm{Eeu} \% 2 \mathrm{Fen} \% 2 \mathrm{Factivities} \% 2 \mathrm{Fsciadvice} \% 2 \mathrm{FLists} \% 2 \mathrm{FE}$ CDC\%2520Reviews\%2Fall\%2520items\%2Eaps

[19] A. P. Fiebelkorn, S. B. Redd, K. Gallagher, P. A. Rota, J. Rota, W. Bellini and J. Seward, "Measles in the United States during the Postelimination Era," Journal of Infectious Diseases, Vol. 202, No. 10, 2010, pp. 1520-1528. doi: $10.1086 / 656914$

[20] J. C. Nmor, H. T. Thanh and K. Goto, "Recurring Measles Epidemic in Vietnam 2005-2009: Implication for Strengthened Control Strategies," International Journal 

Measles, Mumps, Hepatitis A (2006-2010)

of Biological Sciences, Vol. 7, No. 2, 2011, pp. 138-146. doi:10.7150/ijbs.7.138
[21] M. Karcheva, "Mumps_Epidemiology," Ph. D. Dissertation, Medical University, Pleven, 2010 (in Bulgarian). 